\title{
A Voltage Control Strategy of VSG Based on Self-Adaptive Inertia Coefficient and Droop Coefficient
}

\author{
Shizhi Lin $\left(\mathbb{D},{ }^{1}\right.$ Lei Lin, ${ }^{2}$ and Buying Wen ${ }^{2}$ \\ ${ }^{1}$ Department of Electric Power Engineering, Fujian College of Water Conservancy and Electric Power, Sanming 366000, China \\ ${ }^{2}$ College of Electrical Engineering and Automation, Fuzhou University, Fuzhou 350116, China \\ Correspondence should be addressed to Shizhi Lin; n180127045@fzu.edu.cn
}

Received 11 January 2021; Revised 25 March 2021; Accepted 7 April 2021; Published 26 April 2021

Academic Editor: Qiuye Sun

Copyright (c) 2021 Shizhi Lin et al. This is an open access article distributed under the Creative Commons Attribution License, which permits unrestricted use, distribution, and reproduction in any medium, provided the original work is properly cited.

With the increasing penetration rate of distributed renewable energy in power systems, the control strategy of virtual synchronous generator (VSG) is widely used for several years. Some existing VSG control strategies have been able to solve the stability problems caused by the abnormal grid voltage, but the effects of the inertia coefficient and the droop coefficient on the voltage stability are not taken into account. In order to further improve the voltage stability of the microgrid system, a voltage control strategy of VSG based on self-adaptive inertia coefficient and droop coefficient is proposed in this paper. When the voltage is far from the steady state, the increase of the inertia coefficient can decrease the voltage deviation. On the contrary, when it is close to the steady state, the decrease of the inertia coefficient can make the system response speed accelerate. According to the real-time voltage deviation, the droop coefficient can change adaptively to decrease the adjusting time and the voltage deviation during the disturbance. Finally, the simulation model of VSG is built by MATLAB/Simulink for conducting simulation experiments. Compared with other strategies, the correctness and effectiveness of the proposed control strategy are validated.

\section{Introduction}

With the energy crisis and environmental pollution becoming increasingly serious, the penetration rate of distributed renewable energy in power systems is constantly increased. Therefore, the renewable energy such as solar and wind has been widely used and studied [1-4]. As an interface between the renewable energy and the grid, the grid-connected inverter plays a significant part in transmitting power to the grid $[5,6]$.

In order to participate in the voltage regulation and frequency modulation of the power grid, droop control is generally applied by the grid-connected inverter, such as the $P-f$ (active power-frequency) characteristic and the $Q-U$ (reactive power-voltage) characteristic. Depending on the capacity of the distributed renewable energy, load power is capable to be uniformly distributed when the microgrid operates in the island mode. Moreover, in the grid-connection mode, the power grid will be supported by the inverter when there is interference caused by power faults
[7-10]. However, the inertia characteristics of the synchronous machine cannot be simulated by droop control. It leads to the poor dynamic performance and weak anti-interference ability of the system $[11,12]$.

To provide inertial support for the system, the concept of virtual synchronous generator (VSG) is proposed by some scholars [13-17]. Based on the rotor motion equation of the synchronous generator, the mechanism and external characteristics can be simulated by VSG. In this way, the antiinterference ability of the grid-connected inverter is enhanced. Many stability problems will be caused when largescale distributed energies are accessed to the power grid. Some of them can be effectively solved with the control strategies of VSG. Due to these advantages, VSG has been widely concerned and applied in recent years.

The control strategy of VSG provides an effective solution to the system stability problems caused by large-scale distributed energy access to power grid. At present, the research on VSG mostly focuses on the active power loop, which aims to simulate the moment of the inertia and the 
damping characteristics of synchronous generator, so as to ensure the frequency stability of the power system. An adaptive VSG algorithm based on bang-bang control is proposed in the article [18], and the virtual inertia is adjusted to the set maximum or minimum value with the change of frequency, which improves the stability of the system frequency. In [19], based on the adaptive inertia control strategy, the relationship between the droop coefficient and the frequency stability is analyzed, and a comprehensive control algorithm combined adaptive inertia and damping is proposed to further improve the frequency stability of the system.

In addition to frequency, voltage is also an important indicator in the power system. In order to maintain the stability of system voltage, the regulation and control is generally realized through the reactive power loop. However, there are few research studies on the reactive power loop of the parameter design and voltage control strategy now. In the paper [20], an adaptive step search strategy is proposed to provide the stability region analysis approach for SoC-based droop control and obtain the droop coefficients coordinated stability region, which ensures that overcharge and overdischarge of battery will not happen. The literature [21] proposes an impedance-based approach to assess the droop coefficients stability region in the power system, which consists of numerous distributed generators.

Many power faults usually occur in the actual operation of the grid, including imbalanced three-phase voltage and harmonic distortion of voltage. Then, the stability of the system would be seriously damaged. In order to avoid excessive current on the system when the grid suffers voltage sag, a control strategy of VSG based on the reactive power compensation is put forward [22]. The negative sequence voltage components will appear when the grid voltage is unbalanced. To suppress the unbalanced current and power oscillations caused by the negative sequence voltage components, a comprehensive control strategy of VSG under unbalanced voltage conditions is proposed [23]. Three subsystems of voltage amplitude control, output power control, and virtual inertia control are added to suppress fault current after grid voltage sags. It is proved that the low voltage ridethrough capability of VSG can be both effectively enhanced under the symmetrical and unsymmetrical sag types [24].

However, the parameters of the reactive power loop are not designed by the above literature studies from the requirements of open-loop gain and cutoff frequency. Besides, the dynamic response characteristics analysis of the system voltage was not deep enough. Hence, in order to further improve the stability of the system voltage, a control strategy of VSG based on self-adaptive inertia coefficient and droop coefficient is presented in this paper. In summary, the main contributions of this approach are described as follows.

(1) Based on the traditional droop control strategy, the integral link is introduced into the reactive power loop of VSG, which alleviates the dynamic response process of the output voltage and the reactive power. At the same time, the impact on the system is reduced.
(2) The characteristics of the inertia coefficient and the droop coefficient are analyzed. Meanwhile, the influence of the equivalent inertia coefficient and the droop coefficient on the system voltage stability is summarized. According to the change law of the output voltage change rate and voltage deviation, the inertia coefficient and the droop coefficient in the reactive power loop can be dynamically changed, so that the system voltage has a smaller deviation and a faster adjustment speed when the power grid fails, and then the dynamic characteristics of the system voltage is improved.

\section{Basic Principles of VSG}

The main circuit topology and control block diagram of VSG are shown in Figure 1. It mainly includes direct current (DC) voltage source, three-phase inverter bridge, LC filter, and transmission line impedance. The output active power $P_{\mathrm{e}}$ and reactive power $Q_{e}$ of VSG are calculated by the instantaneous power theory [25], as follows:

$$
\begin{aligned}
& P_{e}=e_{o \alpha} i_{\alpha}+e_{o \beta} i_{\beta}, \\
& Q_{e}=e_{o \beta} i_{\alpha}-e_{o \alpha} i_{\beta} .
\end{aligned}
$$

Here, $e_{o \alpha}$ and $e_{o \beta}$ are the fundamental waves of the inverter bridge midpoint voltage in the $\alpha \beta$ coordinate system. $i_{\alpha}$ and $i_{\beta}$ are the current of the filter inductor in the $\alpha \beta$ coordinate system.

The three-phase modulation waves $e_{a}, e_{b}$, and $e_{c}$ can be acquired by the VSG module and the voltage and current double closed-loop control module. With the pulse width modulation (PWM) module, the driving signal of the threephase bridge can be generated by three-phase modulation waves to control the switch. The Materials and Methods section should contain sufficient detail so that all procedures can be repeated. It may be divided into headed subsections if several methods are described.

The power control loop of VSG is divided into the active power loop and the reactive power loop. According to the rotor motion equation of the synchronous generator, the damping and the inertia characteristics of synchronous generator are simulated by the active power loop of VSG. The control block diagram of the active power loop is indicated in Figure 2.

$$
\left\{\begin{array}{l}
J \frac{d \omega}{d t}=\frac{P_{\text {set }}}{\omega_{n}}-\frac{P_{e}}{\omega_{n}}-\left(D_{p}+\frac{k_{\omega}}{\omega_{n}}\right)\left(\omega-\omega_{n}\right) \\
\frac{d \theta}{d t}=\omega .
\end{array},\right.
$$

Here, $\omega$ is the mechanical angular velocity of the synchronous generator, $\omega_{n}$ is the rated rotor angular velocity, $K_{\omega}$ is the droop coefficient between active power and frequency, $J$ is the virtual inertia, $D_{p}$ is the damping coefficient, $P_{s e t}$ and $P_{e}$ are the given value of the active power and the output active power, respectively, and $\theta$ is the phase angle of output voltage. 


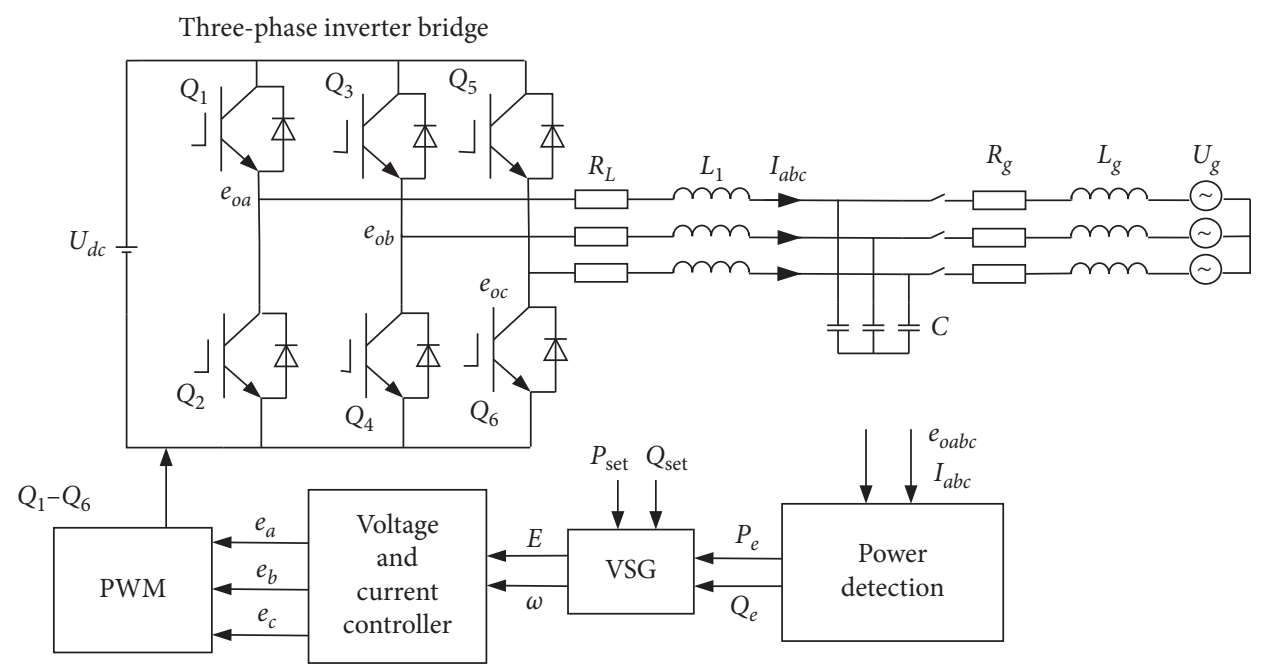

FIgURE 1: The main circuit topology and control block diagram of VSG.

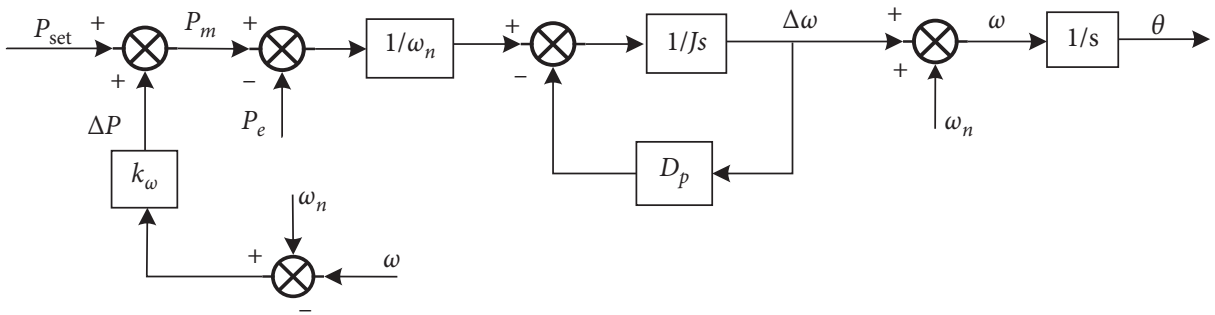

FIgURE 2: The active-power loop of VSG.

As an important part of the synchronous generator, the excitation control system can maintain the constant voltage of generator terminal and improve the stability of power system. The traditional droop control is usually applied to simulate the excitation regulation of synchronous generator by VSG, as shown in Figure 3. However, the dynamic response of excitation regulation is usually described by the first-order inertia link. So, the reactive power control loop of VSG is improved as shown in Figure 4. The integral link is introduced into the reactive power loop to realize the nodifference control during the grid-connected operation, and the dynamic response process of the output voltage and reactive power can be alleviated $[14,15]$. In the case of electricity interruption, the impact on the system can be reduced, and the anti-interference ability of the system is able to improve at the meantime.

$$
Q_{\text {set }}-Q_{e}+D_{q}\left(\sqrt{2} U_{n}-\sqrt{2} E_{m}\right)=K \frac{d\left(\sqrt{2} E_{m}\right)}{d t} .
$$

The control equation of the reactive power loop is depicted in equation (3). $Q_{\text {set }}$ and $Q_{e}$ are the given value of reactive power and the output reactive power, respectively. $K$ is the inertia coefficient of the reactive power loop, $D_{q}$ is the droop coefficient between reactive power and voltage, $U_{n}$ is the rated voltage amplitude, and $E_{m}$ is the valid value of the reference voltage.

\section{Adaptive Inertial Coefficient and Droop Coefficient Control Strategy}

According to the characteristics of the synchronous generator model, it can be concluded that the voltage stability is closely linked with the inertia coefficient and droop coefficient of the reactive power loop.

Equation (3) is rearranged into another form, as follows:

$$
K \frac{d u}{d t}=\Delta Q-D_{\mathrm{q}} \Delta u,
$$

where $\Delta Q$ is the reactive power deviation and $\Delta u$ is the voltage deviation.

As can be seen from Figure 5, the change rate of the output voltage is increased with the decrease of $K$. The microgrid system will be severely affected owing to the excessive change rate of output voltage. Therefore, the increase of $K$ can weaken the voltage change rate. Then, the inertia coefficient $K$ is a virtual analog quantity introduced through the virtual synchronous machine control, so it can be flexibly changed within its value range. 


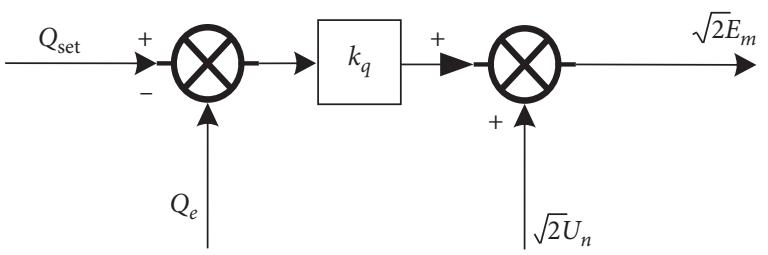

FIgURE 3: The traditional reactive power loop of VSG.

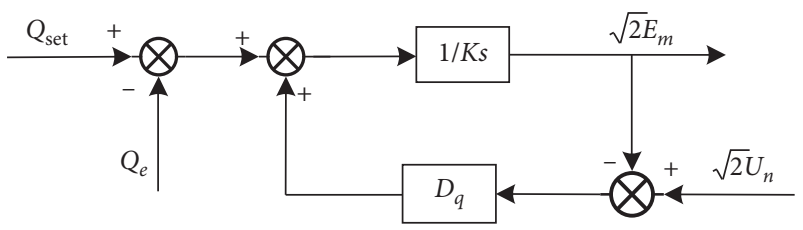

FIgURE 4: The improved reactive power loop of VSG.

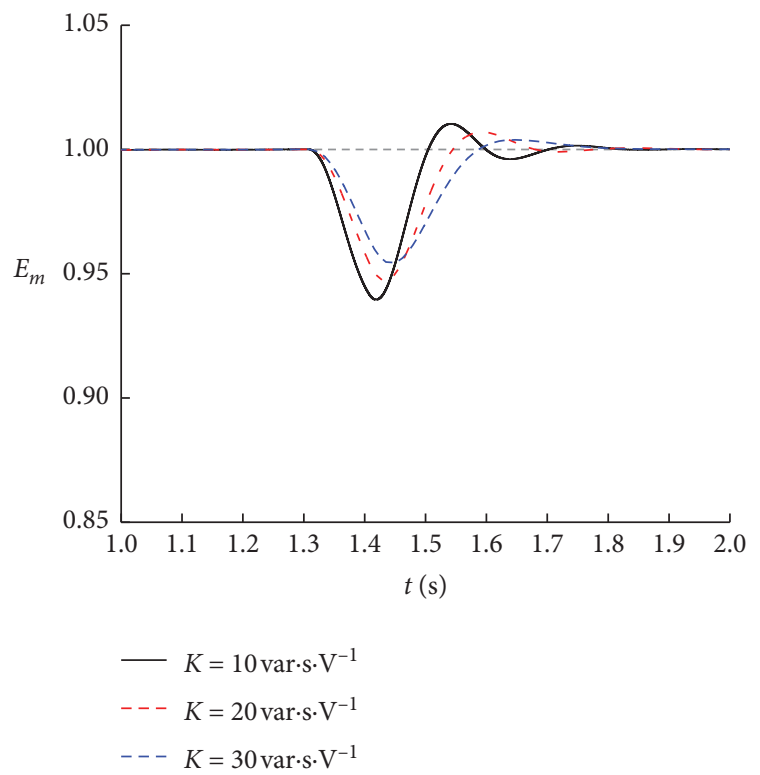

Figure 5: The response characteristics of output voltage with different inertia coefficients.

Rearranging equation (4), the relation between the droop coefficient $D_{q}$ and the voltage deviation $\Delta u$ is depicted as follows:

$$
D_{\mathrm{q}} \Delta u=\Delta Q-K \frac{d u}{d t} .
$$

As shown from Figure 6, the steady-state voltage deviation $\Delta u$ is decreased with the increase of $D_{q}$. Furthermore, the adjusting time is shortened when the output voltage tends to stabilize. Therefore, to further improve the response characteristics of the system voltage, the value of $D_{q}$ can be increased appropriately during the voltage recovery process.

Through the above analysis, a self-adaptive control strategy of VSG is proposed as follows:

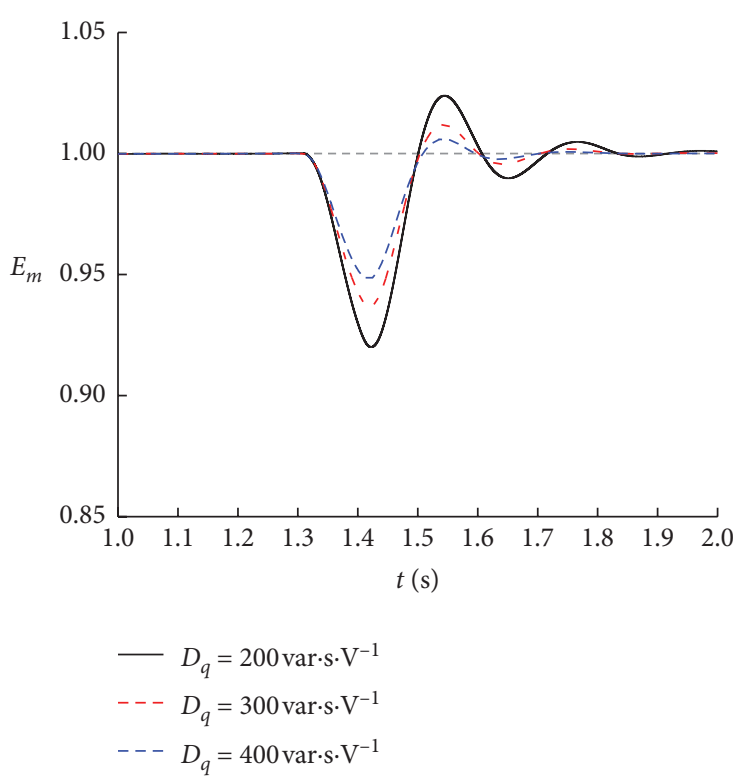

FIGURE 6: The response characteristics of output voltage with different droop coefficients.

$$
\begin{aligned}
& K=\left\{\begin{array}{l}
K_{\max }, \quad \Delta u \frac{d u}{d t}>0 \cap\left|\frac{d u}{d t}\right|>V_{k}, \\
K_{\min }, \quad \Delta u \frac{d u}{d t} \leq 0 \cap\left|\frac{d u}{d t}\right|>V_{k}, \\
K_{s}, \quad\left|\frac{d u}{d t}\right| \leq V_{k},
\end{array}\right. \\
& D_{q}=\left\{\begin{array}{l}
D_{q o}, \quad \Delta u \frac{d u}{d t}>0, \\
D_{q o}+k_{d}|\Delta u|, \quad \Delta u \frac{d u}{d t} \leq 0 \cap\left|\frac{d u}{d t}\right|>V_{d}, \\
D_{q o}, \quad \Delta u \frac{d u}{d t} \leq \cap\left|\frac{d u}{d t}\right| \leq V_{d},
\end{array}\right.
\end{aligned}
$$

where $K_{\max }$ and $K_{\min }$ are the maximum and minimum values of the inertia coefficient, respectively, $K_{s}$ is the inertia coefficient in steady state, $D_{q o}$ is the initial droop coefficient of the reactive power loop, $V_{\mathrm{k}}$ and $V_{\mathrm{d}}$ are the threshold of the output voltage change rate, and $k_{d}$ is the regulation coefficient between the voltage deviation and the droop coefficient.

As the system is in steady state, small disturbance of the output voltage will result in frequent changes of the inertia coefficient $K$. The threshold $V_{\mathrm{k}}$ is set to filter out the fluctuations when the change rate $\mathrm{d} u / \mathrm{d} t$ is near zero. When $\mathrm{d} u / \mathrm{d} t$ exceeds $V_{\mathrm{k}}$, the inertia coefficient $K$ is adaptively changed to the maximum or minimum values with the product of the voltage change rate and the voltage deviation. Meanwhile, the steady inertia coefficient $K_{s}$ is set for the case that $\mathrm{d} u / \mathrm{d} t$ is less than $V_{\mathrm{k}} . K_{\mathrm{s}}$ is selected between the minimum and maximum values of the inertia coefficient. 
Furthermore, depending on the real-time voltage deviation, the droop coefficient $D_{q}$ is adaptively increased so that the dynamic response speed of the system will be accelerated.

\section{Stability Proof and Parameter Range Setting}

4.1. Stability Proof. The conditions for stable operation of grid-connected inverters are stipulated by the network operation standard EN 50438. The grid voltage amplitude shall be maintained between $90 \%$ and $110 \%$ of the rated voltage amplitude [26]. According to the above operation standard, the initial droop coefficient of the reactive power loop can be set with a reasonable setting principle [27]. The rated capacity of a single inverter is assumed to be $10 \mathrm{kV} \mathrm{A}$. It is required that the change of $100 \%$ output reactive power $(\Delta$ $\left.Q_{\max }=10 \mathrm{kvar}\right)$ corresponds to the change of $10 \%$ grid nominal voltage. So, the initial droop coefficient $D_{\text {qo }}$ can be obtained as follows:

$$
D_{\mathrm{qo}}=\frac{\Delta Q_{\max }}{\Delta U_{\max }}=\frac{10000}{220 \sqrt{2} \times 10 \%}=321\left(\frac{\mathrm{var}}{\mathrm{V}}\right) .
$$

The equivalent circuit of VSG operating in grid-connected mode is shown in Figure 7, where $E \angle \delta$ and $Z_{\mathrm{o}}$ are the output voltage and the equivalent output impedance of the inverter, respectively. $U_{\mathrm{g}}$ is the grid voltage, $Z_{\mathrm{g}}$ is the line impedance between the output point of the inverter and the point of common coupling (PCC), $Z$ is defined as the sum of $Z_{\mathrm{o}}$ and $Z_{\mathrm{g}}$, and $R$ and $X_{\mathrm{s}}$ are the resistive and inductive parts of $Z$. It is generally that the value of $X_{\mathrm{s}}$ is much greater than that of $R$. The active and reactive power transmitted to the grid power by the inverter, are shown in equations (9) and (10), respectively.

$$
\begin{aligned}
& P=\frac{3 E U_{g}}{X_{s}} \sin \delta, \\
& Q=\frac{3\left(E-U_{\mathrm{g}} \cos \delta\right) E}{X_{\mathrm{s}}} .
\end{aligned}
$$

In order to simplify the analysis, the control between the active power loop and the reactive power loop can be regarded as approximate decoupling in this paper. According to Figure 7 and equations (2), (3), (9), and (10), the small signal equivalent model of VSG in $s$ domain can be obtained in Figure 8.

According to the small signal equivalent model of VSG, the open-loop transfer function and the closed-loop transfer function of the reactive power loop can be deduced, as shown in equations $S_{1}(\mathrm{~s})$ and $S_{2}(\mathrm{~s})$ :

$$
\begin{aligned}
& S_{1}(s)=\frac{3\left(2 E_{n}-U_{g}\right)}{\sqrt{2} X_{s} K s+\sqrt{2} X_{s} D_{q}}, \\
& S_{2}(s)=\frac{3\left(2 E_{n}-U_{g}\right)}{\sqrt{2} X_{s} K s+\sqrt{2} X_{s} D_{q}+3\left(2 E_{n}-U_{g}\right)} .
\end{aligned}
$$

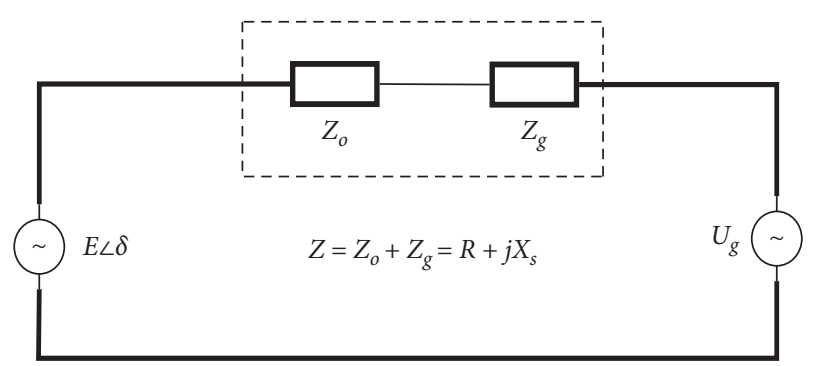

FIGURE 7: The equivalent circuit of VSG operating in the gridconnected mode.

Using the inertia coefficient $K$ and the droop coefficient $D_{q}$ as variables, respectively, the Bode diagram and the closed-loop pole distribution diagram of the transfer function $S_{2}(s)$ are drawn. Meanwhile, the influence of the two coefficients on the dynamic characteristics of the reactive power loop is analyzed.

The Bode diagram of the transfer function $S_{2}(\mathrm{~s})$ is depicted in Figure 9. It can be seen that when the droop coefficient $D_{q}$ remains unchanged, the increase of the equivalent inertia coefficient $K$ will reduce the bandwidth of the reactive power loop. When $K$ remains unchanged, the bandwidth of the reactive power loop decreases with the increase of $D_{q}$.

The pole distribution diagram of the closed-loop transfer function $S_{2}(\mathrm{~s})$ is depicted in Figure 10. With the increase of the inertia coefficient $K$, the closed-loop poles of the reactive power loop will gradually get closer to the virtual axis, and the distribution becomes more and more intensive. At the same time, the absolute value of the closed-loop pole decreases gradually, and the response speed of the system slows down. In addition, with the increase of the droop coefficient $D_{q}$, the closed-loop poles gradually move away from the imaginary axis, and the distribution is relatively uniform. Meanwhile, the absolute value of the closed-loop pole increases gradually, and then, the response speed of the system increases accordingly.

4.2. Parameter Range Setting. It is described from equation (11) that the reactive power loop is a typical first-order inertia link, including the proportional module $P_{i}$ and the first-order low pass filter module $G(\mathrm{~s})$.

The expressions of $P_{\mathrm{i}}$ and $G(\mathrm{~s})$ are shown in equations (14) and (15):

$$
\begin{aligned}
S_{1}(s) & =\frac{3\left(2 E_{\mathrm{n}}-U_{\mathrm{g}}\right)}{\sqrt{2} X_{\mathrm{s}} D_{\mathrm{q}}} \cdot \frac{1}{\left(K / D_{q}\right) s+1}=P_{\mathrm{i}} \cdot G(\mathrm{~s}), \\
P_{i} & =\frac{3\left(2 E_{n}-U_{g}\right)}{\sqrt{2} X_{s} D_{q}}, \\
G(\mathrm{~s}) & =\frac{1}{\left(K / D_{q}\right) s+1} .
\end{aligned}
$$




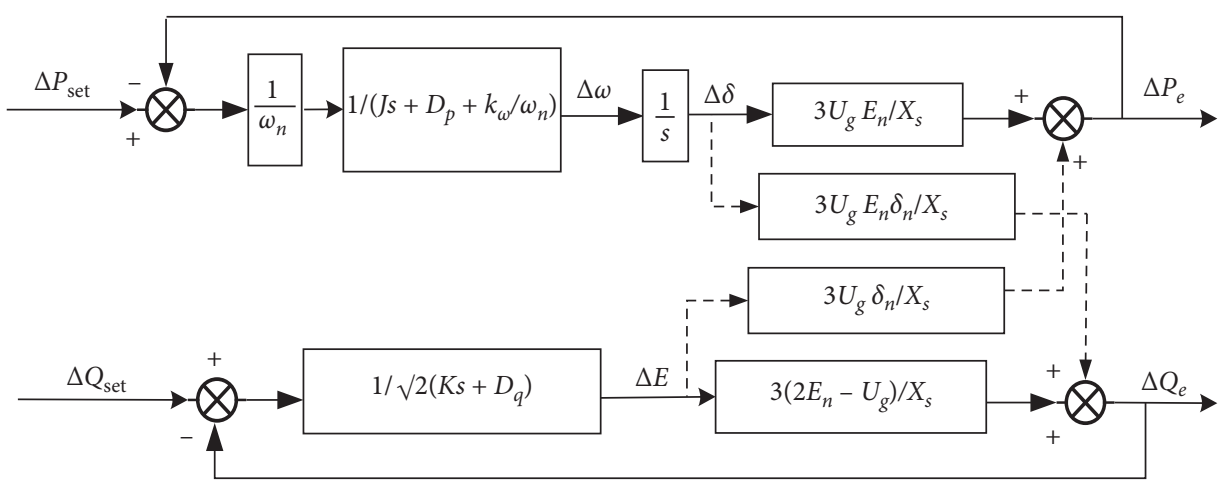

FIgURE 8: The small signal equivalent model of VSG in s domain.

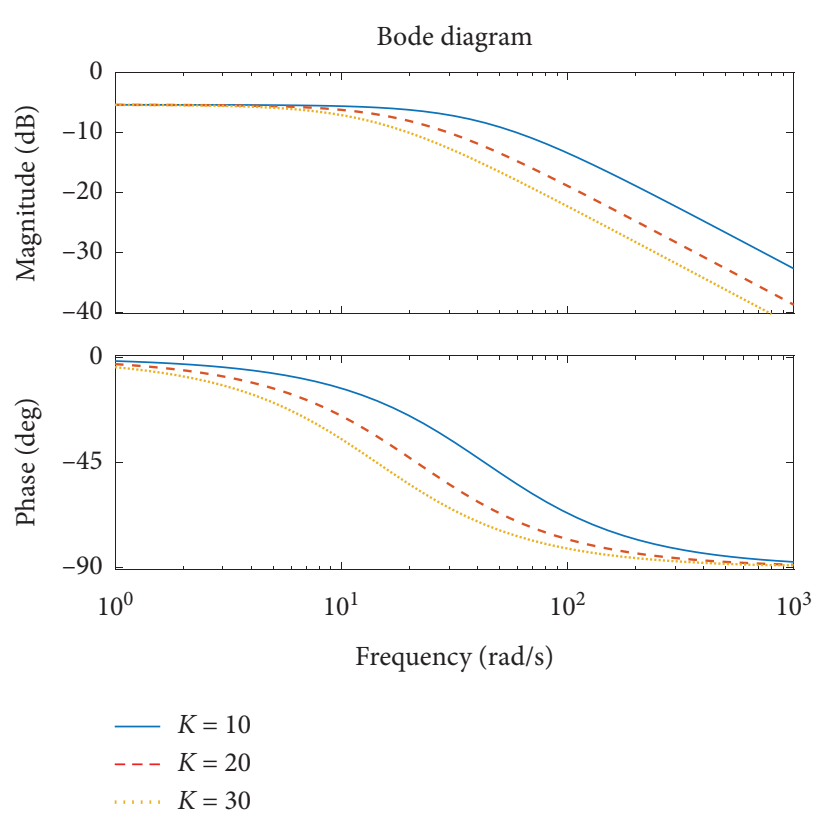

(a)
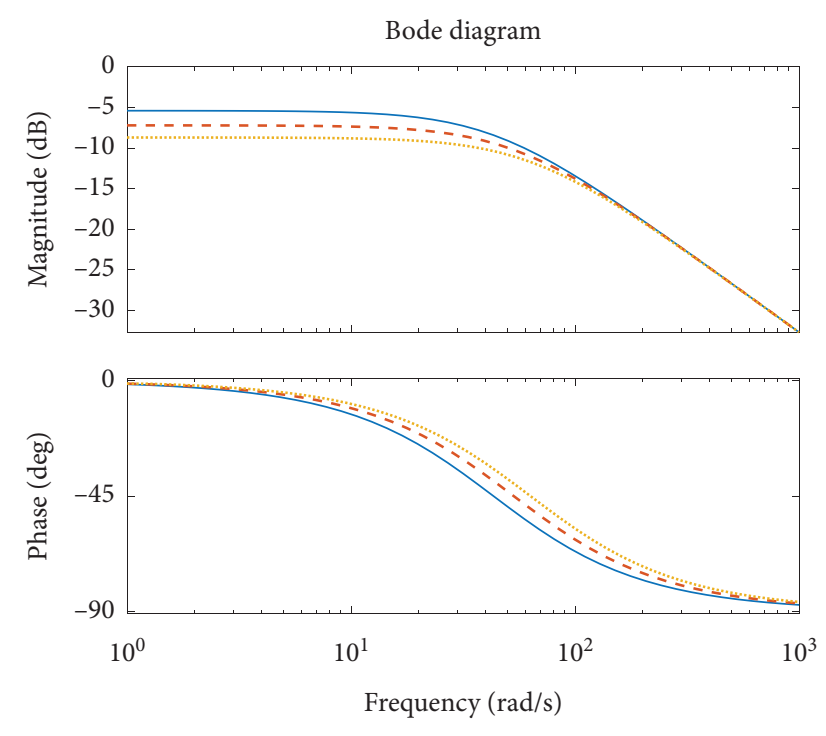

$$
\begin{aligned}
-D_{q} & =200 \\
---D_{q} & =300 \\
\cdots \cdots D_{q} & =400
\end{aligned}
$$

(b)

Figure 9: The Bode diagram of the transfer function $S_{2}(\mathrm{~s})$.

For restraining the impact of twice the power frequency pulsation in the reactive power on the output voltage amplitude, the corner frequency $f_{L Q}$ of the first-order low pass filter should be less than $10 \%$ of twice the power frequency pulsation:

$$
f_{L Q}=\frac{D_{q}}{2 \pi K}<\frac{1}{10} 2 f_{p} .
$$

By rearranging equation (16), the minimum value of the inertia coefficient $K$ can be obtained as follows:

$$
K>\frac{5 D_{q}}{2 \pi f_{p}} .
$$

According to the grid operation standards GB/T 31464-2015, the principles of hierarchical partition and local balance need to be taken for the strategies of grid voltage control. Therefore, the response time of grid voltage regulation is significantly less than that of frequency modulation for the system. The dynamic response time of grid voltage can be controlled within 1 second by the existing research studies, which are concerning hierarchical and zonal coordinated control of grid voltage. Assume that the response time $t_{\mathrm{s}}$ of VSG participating in grid voltage regulation is approximately equal to the response time $t_{s q}$ of the reactive power loop:

$$
\begin{aligned}
T & =\frac{K}{D_{q}}, \\
t_{s q} & =3 T=\frac{3 K}{D_{q}} .
\end{aligned}
$$




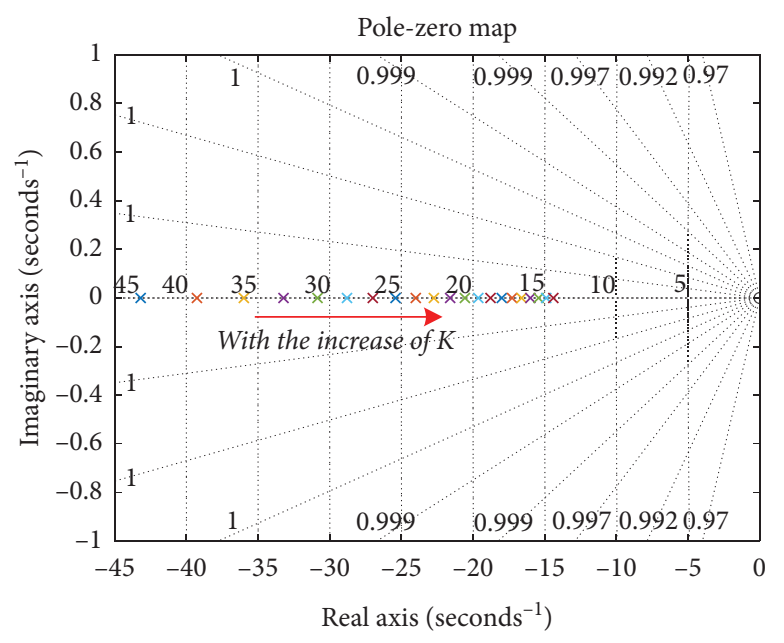

(a)

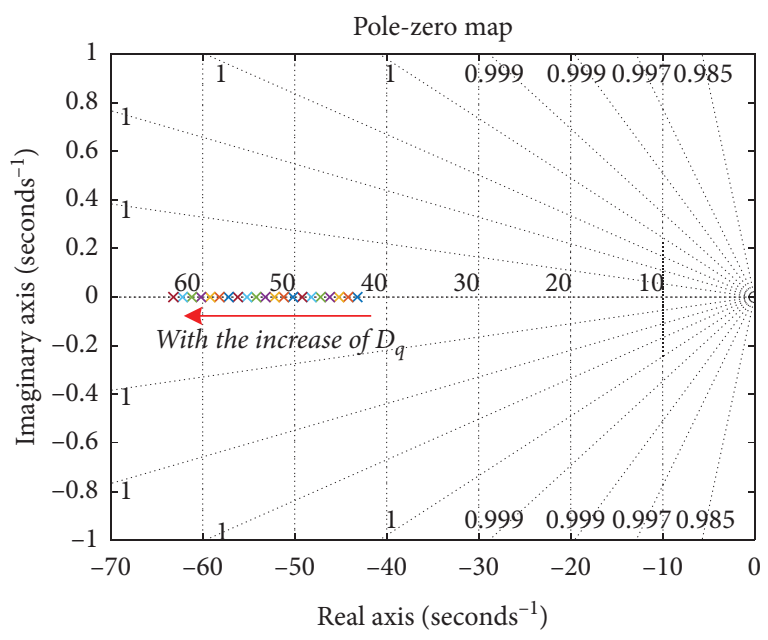

(b)

Figure 10: The pole distribution diagram of the closed-loop transfer function $S_{2}$ (s).

As shown in equations (18) and (19), $T$ is the constant time of the first-order system. According to the definition of dynamic performance metrics for the first-order system, $t_{s q}$ is triple the constant time $T$.

Furthermore, a certain margin should be considered, so the response time $t_{s q}$ is set to $t_{\mathrm{sq}}<0.4 \mathrm{~s}$. Combining equations (18) and (19), the maximum value of $K$ can be obtained by

$$
K<\frac{2}{15} D_{q}
$$

\section{Simulation Results}

In order to verify the validity of the proposed control strategy in this paper, the simulation model of VSG is built by MATLAB/Simulink for conducting simulation experiments. The main parameter settings of the VSG control system are listed in Table 1.

For the strategy I, the traditional droop control is applied in the reactive power loop of VSG, as rendered in Figure 3. The main parameters are set as $k_{q}=0.006$ and $U_{n}=220 \mathrm{~V}$. For the strategy II, the inertia coefficient $K$ and the droop coefficient $D_{q}$ of the reactive power loop are set as 21 var.s/V and $321 \mathrm{var} / \mathrm{V}$, respectively. For the strategy III proposed in this paper, the control strategies are shown in formulas (6) and (7). Some main simulation parameters of the strategy III are set in Table 2 .

The structure diagram of a single VSG is shown in Figure 11. When the simulation model is running in the grid-connected mode, the active power of $2 \mathrm{~kW}$ is transmitted from the inverter to the grid in the initial. In order to simulate the situation of grid voltage faults, the amplitude of the grid phase voltage is made to drop by $10 \%$ at $1.6 \mathrm{~s}$ suddenly, and then it will restore to the rated value after $0.1 \mathrm{~s}$. The control effects of the three strategies are compared in the same simulation conditions.
The simulation results are shown in Figure 12. When the grid voltage drops suddenly at $1.6 \mathrm{~s}$. For the strategy I, the output voltage will drop rapidly due to the lack of inertia in the voltage regulation. Compared with the other two strategies, the strategy I has a much larger voltage deviation. With the reactive power loop of VSG improved, the voltage deviation of the strategy II can be reduced to $18.542 \mathrm{~V}$. Among the three strategies, the strategy III has the smallest voltage deviation about $15.179 \mathrm{~V}$, which is reduced by $18.137 \%$ relative to the strategy II. Furthermore, the strategy III has the shortest adjusting time and the smallest oscillation amplitude in the process of voltage restoration to the rated value.

The change curves of the inertia coefficient $K$ and droop coefficient $D_{q}$ in the strategy III are, respectively, shown in Figures 13 and 14. It can be concluded from the simulation results that the response characteristics of the system voltage will be significantly improved by the self-adaptive control of $K$ and $D_{q}$.

Similarly, the simulation experiments are conducted in the case that the amplitude of grid phase voltage rises suddenly. As the simulation results shown in Figure 15, the control effects of the three strategies are basically the same as those when the grid voltage drops.

To further verify the correctness and compatibility of the strategy III in different operating conditions, the simulation model of two VSGs running in parallel is also built, as shown in Figure 16. The rated capacity ratio of two VSGs is set to $3: 2$. Some main simulation parameters are listed in Table 3.

The simulation results can be obtained in Figures 17 and 18. The control effect of the strategy III is the best among the three strategies. It is observed that the strategy III has the shortest steady adjusting time and the minimum voltage deviation. Thus, when the two VSGs are running in parallel, the control effects of the three strategies are basically the same as those when a single VSG is running independently. 
TABLE 1: VSG control system parameter settings.

\begin{tabular}{lcc}
\hline Parameters & Descriptions & Values \\
\hline$U_{d c}$ & DC voltage & $800 \mathrm{~V}$ \\
$U_{g}$ & Grid voltage & $220 \mathrm{~V}$ \\
$L_{1}$ & Filter inductance & $3.2 \mathrm{mH}$ \\
$L_{g}$ & Grid-side inductance & $3.2 \mathrm{mH}$ \\
$C$ & Filter capacitor & $14 \mu \mathrm{F}$ \\
$S_{N}$ & Rated capacity of VSG & $10 \mathrm{kV} \mathrm{A}$ \\
$f_{p}$ & Power frequency & $50 \mathrm{~Hz}$ \\
$f_{s}$ & Switching frequency & $5 \mathrm{kHz}$ \\
$J$ & Inertia coefficient & $0.45 \mathrm{~kg} \mathrm{~m} \mathrm{~m}^{2}$ \\
$D_{p}$ & Droop coefficient & $30 \mathrm{Nm} \mathrm{s} / \mathrm{rad}$ \\
$D_{q o}$ & Initial droop coefficient & $321 \mathrm{var} / \mathrm{V}$ \\
\hline
\end{tabular}

TABle 2: Parameters settings for the strategy III.

\begin{tabular}{lcc}
\hline Parameters & Description & Value \\
\hline$K_{\min }$ & Minimum inertia coefficient & $6 \mathrm{var} \cdot \mathrm{s} / \mathrm{V}$ \\
$K_{s}$ & Inertia coefficient in steady state & $21 \mathrm{var} \cdot \mathrm{s} / \mathrm{V}$ \\
$K_{\max }$ & Maximum inertia coefficient & $36 \mathrm{var} \cdot \mathrm{s} / \mathrm{V}$ \\
$V_{k}$ & Voltage change rate threshold & $16 \mathrm{~V} \cdot \mathrm{s}^{-1}$ \\
$V_{d}$ & Voltage change rate threshold & $4 \mathrm{~V} \cdot \mathrm{s}^{-1}$ \\
$k_{d}$ & Correlation coefficient & $20 \mathrm{var} \cdot \mathrm{V}^{-2}$ \\
\hline
\end{tabular}

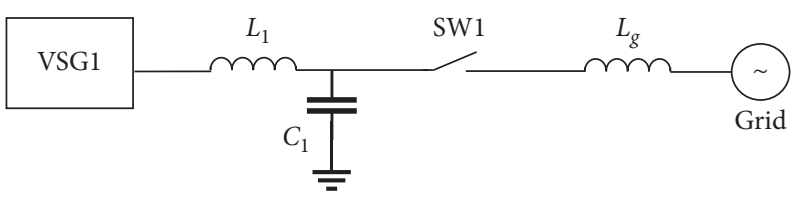

FIgURE 11: The equivalent structure diagram of a single VSG.

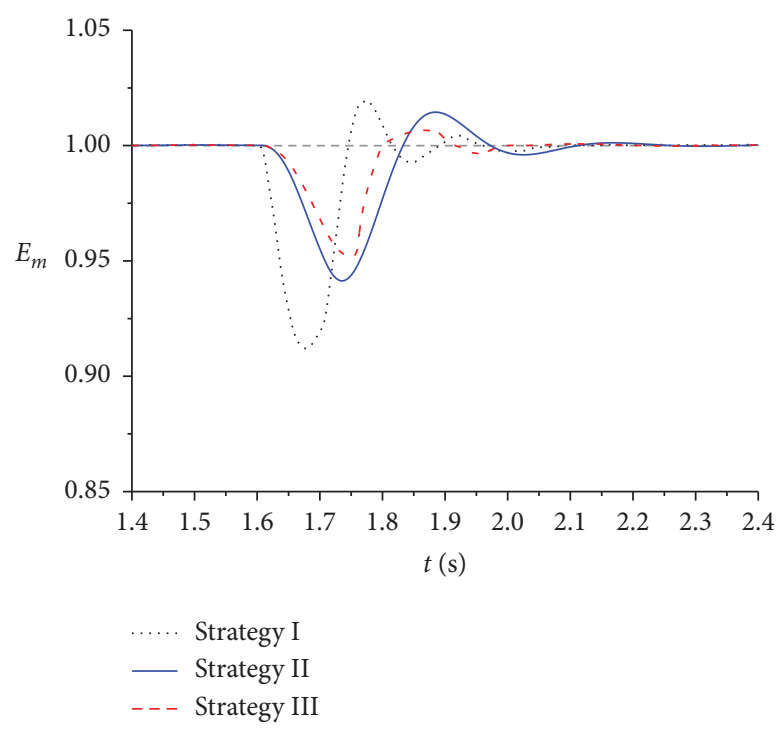

Figure 12: The comparison of control effects among different strategies when the grid voltage drops. 


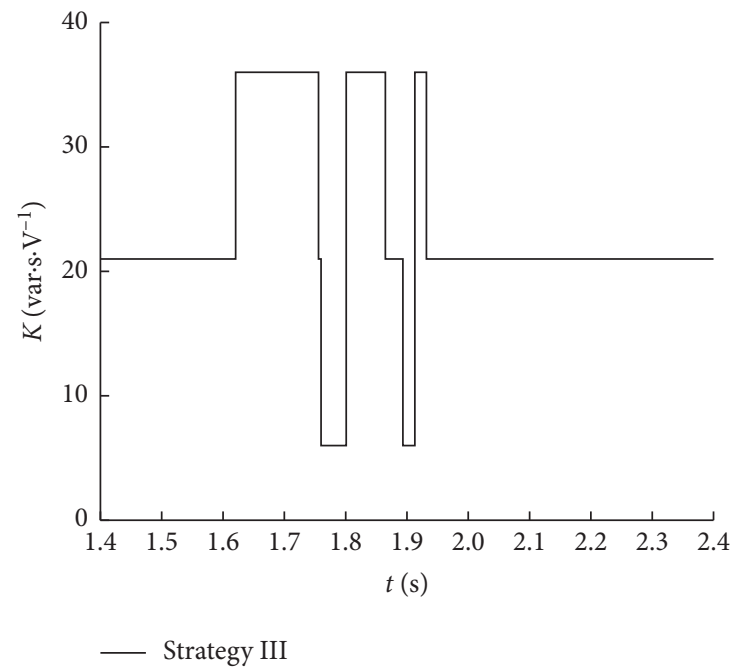

FIgURE 13: The curve of inertia coefficient for the strategy III.

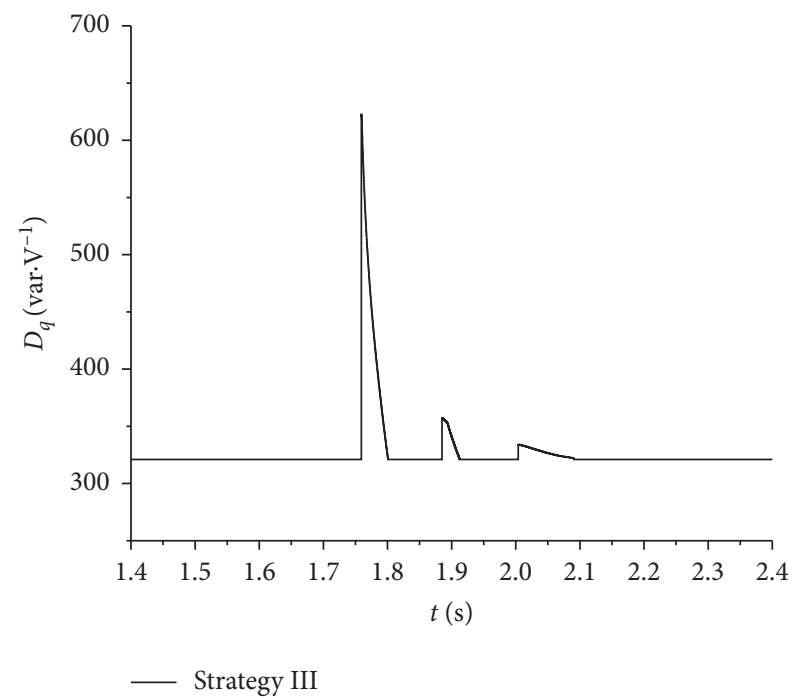

Figure 14: The curve of droop coefficient for the strategy III.

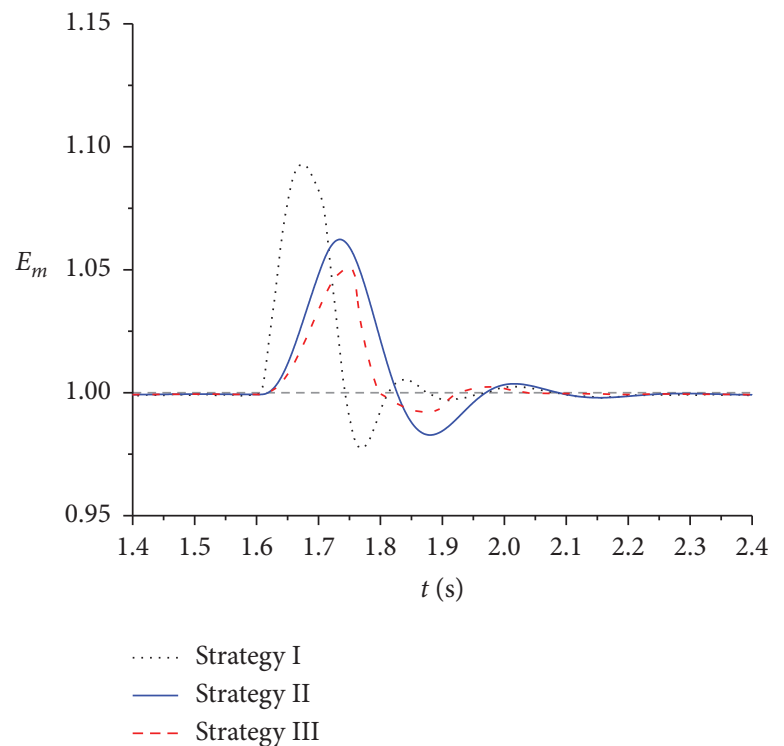

FIGURE 15: The comparison of control effects among different strategies when the grid voltage rises. 


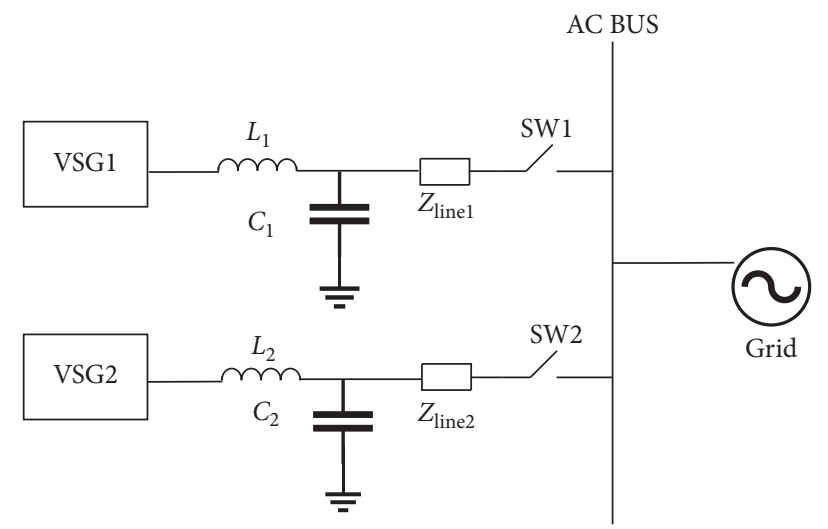

FIgURE 16: The structure diagram of parallel operation.

TABLe 3: Parameters settings of the two VSGs.

\begin{tabular}{lcc}
\hline Parameter & Description & Value \\
\hline$J_{1}$ & Virtual inertia & $0.45 \mathrm{~kg} \cdot \mathrm{m}^{2}$ \\
$J_{2}$ & Virtual inertia & $0.3 \mathrm{~kg} \cdot \mathrm{m}^{2}$ \\
$D_{p 1}$ & Droop coefficient & $30 \mathrm{~N} \mathrm{~m} \mathrm{~s} / \mathrm{rad}$ \\
$D_{p 2}$ & Droop coefficient & $20 \mathrm{~N} \mathrm{~m} \mathrm{~s} / \mathrm{rad}$ \\
$K_{1}$ & Inertia coefficient & $21 \mathrm{var} \cdot \mathrm{s} / \mathrm{V}$ \\
$K_{2}$ & Inertia coefficient & $14 \mathrm{var} \cdot \mathrm{s} / \mathrm{V}$ \\
$D_{q 1}$ & Droop coefficient & $321 \mathrm{var} / \mathrm{V}$ \\
$D_{q 2}$ & Droop coefficient & $214 \mathrm{var} / \mathrm{V}$ \\
\hline
\end{tabular}

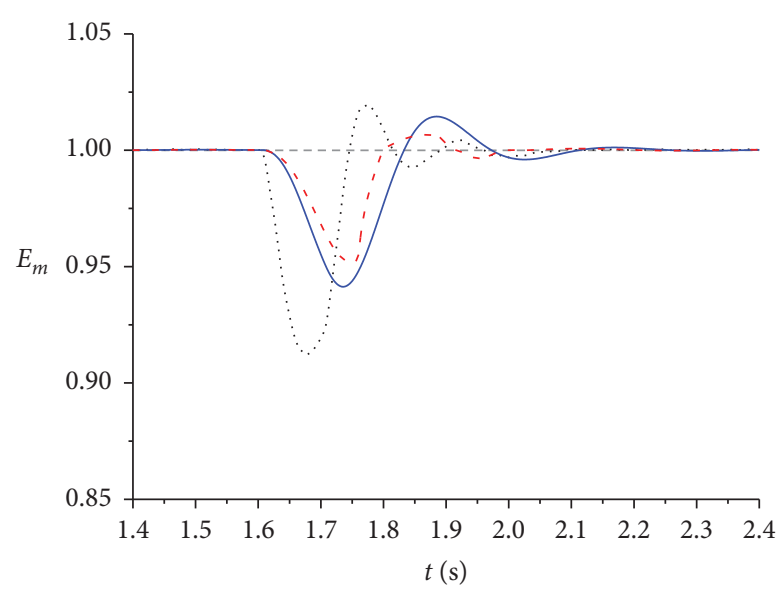

$\begin{array}{ll}\ldots . . . & \text { Strategy I } \\ - & \text { Strategy II } \\ -\ldots & \text { Strategy III }\end{array}$

(a)

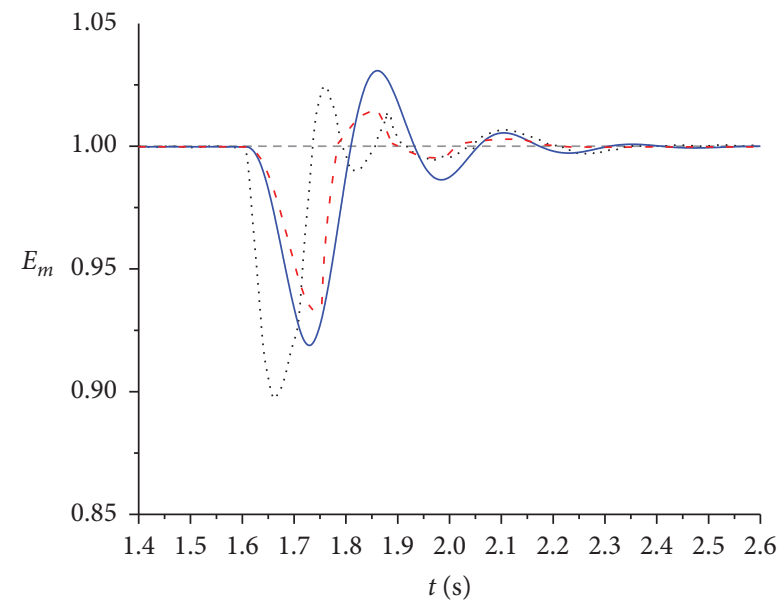

…. Strategy I
— Strategy II
- - - Strategy III

(b)

FIGURE 17: The response curve of output voltage when the grid voltage drops. (a) Curve of VSG1. (b) Curve of VSG2. 


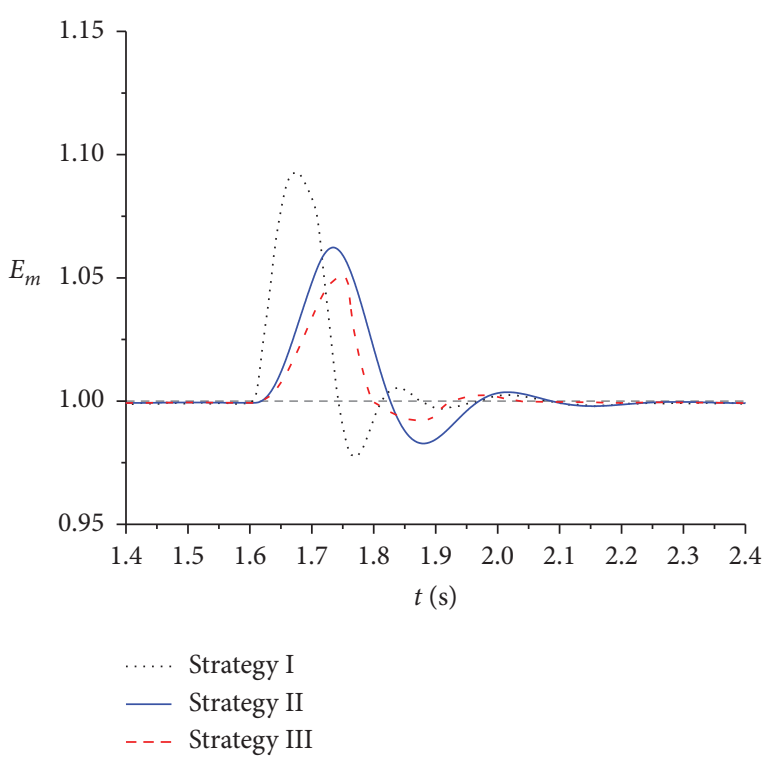

(a)

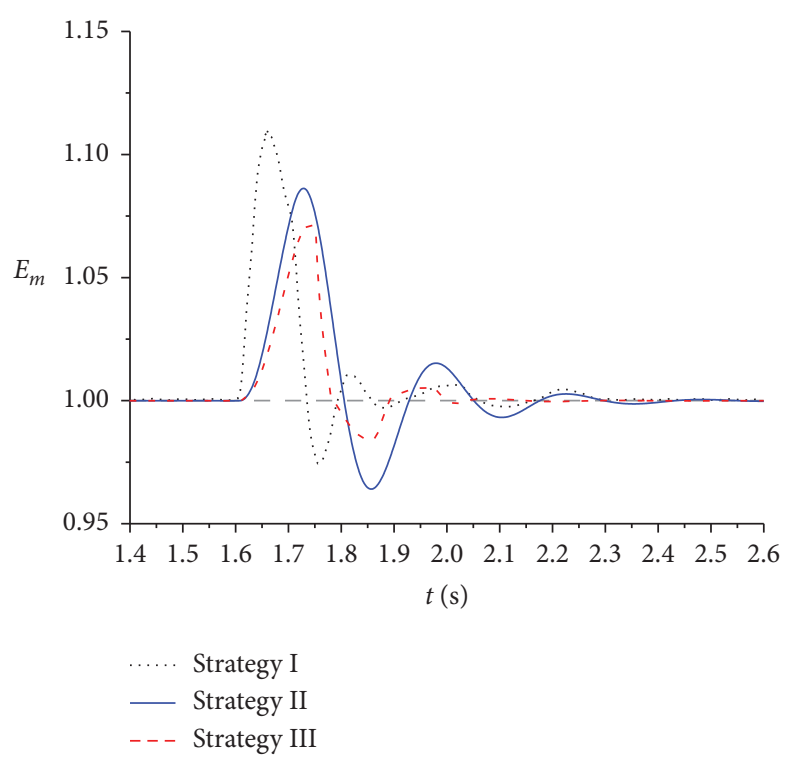

(b)

Figure 18: The response curve of output voltage when the grid voltage rises. (a) Curve of VSG1. (b) Curve of VSG2.

To sum up, the validity and compatibility of the strategy III are proved by the simulation results.

\section{Conclusions}

In order to improve the voltage stability of the system, a self-adaptive control strategy of VSG combining the inertia coefficient, and the droop coefficient is presented in this paper. For the purpose to weaken the impact on the system, a larger inertia coefficient will be adopted to reduce the voltage change rate. Instead, the recovery speed of output voltage is accelerated with the reduction of inertia coefficient. In addition, the adjusting time and the voltage deviation can be decreased by self-adaptive control of the droop coefficient. The transient process of the system is shortened so that the output voltage can restore to the steady state much faster. Finally, the effectiveness of the proposed method is demonstrated through the simulation results.

\section{Data Availability}

All data generated or analyzed during this study are included within the article.

\section{Conflicts of Interest}

The authors declare that there are no conflicts of interest the regarding of the publication of this article.

\section{Acknowledgments}

This research was supported by the National Natural Science Foundation of China (51707040).

\section{References}

[1] T. L. Vandoorn, B. Meersman, J. D. M. De Kooning, and L. Vandevelde, "Directly-coupled synchronous generators with converter behavior in islanded microgrids," IEEE Transactions on Power Systems, vol. 27, no. 3, pp. 1395-1406, 2012.

[2] F. Blaabjerg, R. Teodorescu, M. Liserre, and A. V. Timbus, "Overview of control and grid synchronization for distributed power generation systems," IEEE Transactions on Industrial Electronics, vol. 53, no. 5, pp. 1398-1409, 2006.

[3] I. Serban and C. P. Ion, "Microgrid control based on a gridforming inverter operating as virtual synchronous generator with enhanced dynamic response capability," International Journal of Electrical Power \& Energy Systems, vol. 89, no. 1, pp. 94-105, 2017.

[4] Q. Sun, R. Han, H. Zhang, J. Zhou, and J. M. Guerrero, "A multiagent-based consensus algorithm for distributed coordinated control of distributed generators in the energy internet," IEEE Transactions on Smart Grid, vol. 6, no. 6, pp. 3006-3019, 2015.

[5] C.-C. Chang, D. Gorinevsky, and S. Lall, "Stability analysis of distributed power generation with droop inverters," IEEE Transactions on Power Systems, vol. 30, no. 6, pp. 3295-3303, 2015.

[6] Y. A. I. Mohamed, M. A. Rahman, and R. Seethapathy, "Robust line-voltage sensorless control and synchronization of LCL-filtered distributed generation inverters for high power quality grid connection," IEEE Transactions on Power Electronics, vol. 27, no. 1, pp. 87-98, 2011.

[7] J. Schiffer, R. Ortega, A. Astolfi, J. Raisch, and T. Sezi, "Stability of synchronized motions of inverter-based microgrids under droop control," IFAC Proceedings Volumes, vol. 47, no. 3, pp. 6361-6367, 2014.

[8] W. Zhang, W. Wang, H. Liu, and D. Xu, "A disturbance rejection control strategy for droop-controlled inverter based on super-twisting algorithm," IEEE Access, vol. 7, pp. 27037-27046, 2019. 
[9] D. C. Raj and D. N. Gaonkar, "Frequency and voltage droop control of parallel inverters in microgrid," in Proceedings of the 2016 2nd International Conference on Control, Instrumentation, Energy \& Communication (CIEC), pp. 407-411

, Kolkata, India, 2016.

[10] Y. Deng, Y. Tao, G. Chen, G. Li, and X. He, "Enhanced power flow control for grid-connected droop-controlled inverters with improved stability," IEEE Transactions on Industrial Electronics, vol. 64, no. 7, pp. 5919-5929, 2017.

[11] M. Kohansal, J. S. Moghani, B. Abdi, and G. B. Gharehpetian, "A control method to enhance dynamic performance of parallel inverters in islanded microgrid," in Proceedings of the International Aegean Conference on Electrical Machines and Power Electronics and Electromotion, Joint Conference, pp. 753-757, Istanbul, Turkey, 2011.

[12] Z. Wang, F. Zhuo, H. Yi, J. Wu, F. Wang, and Z. Zeng, "Analysis of dynamic frequency performance among voltagecontrolled inverters considering virtual inertia interaction in microgrid," IEEE Transactions on Industry Applications, vol. 55, no. 4, pp. 4135-4144, 2019.

[13] Y. Chen, R. Hesse, D. Turschner, and H. Beck, "Improving the grid power quality using virtual synchronous machines," in Proceedings of the 2011 International Conference on Power Engineering, Energy and Electrical Drives, pp. 1-6, Malaga, Spain, 2011.

[14] Q.-C. Zhong and G. Weiss, "Synchronverters: inverters that mimic synchronous generators," IEEE Transactions on Industrial Electronics, vol. 58, no. 4, pp. 1259-1267, 2011.

[15] Q. Zhong, P. Nguyen, Z. Ma, and W. Sheng, "Self-Synchronized synchronverters: inverters without a dedicated synchronization unit," IEEE Transactions on Power Electronics, vol. 29, no. 2, pp. 617-630, 2014.

[16] J. Liu, Y. Miura, and T. Ise, "Comparison of dynamic characteristics between virtual synchronous generator and droop control in inverter-based distributed generators," IEEE Transactions on Power Electronics, vol. 31, no. 5, pp. 36003611, 2016.

[17] J. Liu, Y. Miura, H. Bevrani, and T. Ise, "Enhanced virtual synchronous generator control for parallel inverters in microgrids," IEEE Transactions on Smart Grid, vol. 8, no. 5, pp. 2268-2277, 2017.

[18] J. Alipoor, Y. Miura, and T. Ise, "Power system stabilization using virtual synchronous generator with alternating moment of inertia," IEEE Journal of Emerging and Selected Topics in Power Electronics, vol. 3, no. 2, pp. 451-458, 2015.

[19] D. Li, Q. Zhu, S. Lin, and X. Y. Bian, "A self-adaptive inertia and damping combination control of VSG to support frequency stability," IEEE Transactions on Energy Conversion, vol. 32, no. 1, pp. 397-398, 2017.

[20] R. Wang, Q. Sun, W. Hu, Y. Li, D. Ma, and P. Wang, "SoCbased droop coefficients stability region analysis of the battery for stand-alone supply systems with constant power loads," IEEE Transactions on Power Electronics, vol. 36, no. 7, pp. 7866-7879, 2021.

[21] R. Wang, Q. Sun, W. Hu, J. Xiao, H. Zhang, and P. Wang, "Stability-oriented droop coefficients region identification for inverters within weak grid: an impedance-based approach," IEEE Transactions on Systems, Man, and Cybernetics: Systems, vol. 51, no. 4, pp. 2258-2268, 2021.

[22] Y. Yang, H. Miao, H. Chen, and C. Zhang, "Voltage sag ridethrough control strategy with reactive power compensation for virtual synchronous generator," in Proceedings of the 2018 13th IEEE Conference on Industrial Electronics and Applications (ICIEA), pp. 1140-1146, Wuhan, China, 2018.
[23] T. Zheng, L. Chen, Y. Guo, and S. Mei, "Comprehensive control strategy of virtual synchronous generator under unbalanced voltage conditions," IET Generation, Transmission \& Distribution, vol. 12, no. 7, pp. 1621-1630, 2018.

[24] J. Alipoor, Y. Miura, and T. Ise, "Voltage sag ride-through performance of virtual synchronous generator," in Proceedings of the 2014 International Power Electronics Conference (IPEC-Hiroshima 2014 - ECCE ASIA), pp. 3298-3305, Hiroshima, Spain, 2014.

[25] H. Akagi and E. H. Watanabe, "Instantaneous power theory and applications to power conditioning," IEEE Xplore, Piscataway, NJ, USA, 2007.

[26] Requirements for the Connection of Micro Generators in Parallel with Public Low-Voltage Distribution Networks, EN 504382008.

[27] H. Wu, X. Ruan, D. Yang et al., "Small-signal modeling and parameters design for virtual synchronous generators," IEEE Transactions on Industrial Electronics, vol. 63, no. 7, pp. 4292-4303, 2016. 